\title{
Los papeles reservados de Fernando VII: Identificación, análisis y propuesta de descripción normalizada
}

\author{
Miguel RodRÍGUEZ CASTILLO \\ Archivo del Congreso de los Diputados \\ miguel-do-carballino@hotmail.com
}

Recibido: Junio 2012

Aceptado: Noviembre 2012

Resumen: Utilizando la metodología de investigación archivística se establece la cadena de la custodia de los ciento ocho volúmenes encuadernados que conforman esta serie y se analiza y describe brevemente en contenido de los mismos, descubriendo de esta manera los temas que suscitaron el interés de Fernando VII. Se propone a su vez una descripción normalizada de estos documentos siguiendo las norma internacional ISAD $(\mathrm{G})$

Palabras clave: Fernando VII; series documentales; Historia Contemporánea de España

The confidential papers of Fernando VII: identification, analysis and proposal for standardized description

\begin{abstract}
Using the archivist methodology of investigation it is established the chain of custody of the hundred and eight binded volumes that form this document series and it is analyzed and briefly described the content of them, discovering this way the subjects of interest for Fernando VII. It's also proposed a normalized description of these documents according to international standard ISAD $(\mathrm{G})$
\end{abstract}

Keywords: Fernando VII; documentary series; Contemporary History of Spain

\section{INTRODUCCIÓN}

La turbulenta situación que se vivió en España y en el mundo a finales del siglo XVIII y principios del XIX: Revolución francesa, la guerra franco-hispana contra el Reino Unido, los movimientos emancipadores en América, etc., ha dado pie a innumerables investigaciones históricas y seguirá siendo caldo de cultivo para muchas otras, ya que marcaron el principio de la edad contemporánea.

En lo que respecta a España, el estudio del reinado de Fernando VII resulta crucial por el papel que jugó nuestro país en los conflictos mundiales y por los cambios sociales que se produjeron, que en muchos casos siguen siendo relevantes en la actualidad. Muchas de las rivalidades que surgieron entonces (absolutistas, liberales radicales y moderados -, carlistas, etc.) han mutado y sobrevivido hasta nuestros días. 
Con este estudio sobre los Papeles Reservados de Fernando VII se pretende dar a conocer una fuente documental de vital importancia para la investigación histórica de esta época.

\subsection{OBJETO DE LA INVESTIGACIÓN: LOS PAPELES RESERVADOS DE FERNANDO VII}

No existe prácticamente bibliografía específica respecto de la documentación objeto de este estudio, sin embargo los papeles reservados son conocidos y citados por la gran mayoría de estudiosos de la época. Destacan, por ejemplo, en los trabajos relativos a las logias masónicas en España, a la independencia de los Estados de América latina, la Guerra de la Independencia, las Guerras Carlistas, estudios sobre la edad contemporánea, etc. Un ejemplo claro y actual de la importancia de estos documentos vino con el 200 aniversario de la Constitución de 1812, lo que originó innumerables estudios de la época que bebieron en muchos casos de la información contenida en los Papeles reservados.

Estos documentos constituyen una serie de carácter facticio, es decir, se trata de una colección de documentos reunidos según criterios subjetivos y que, por lo tanto, no conservan su estructura original ni respetan el principio de procedencia. Los documentos que la conforman hacen referencia a los reinados de Carlos III, Carlos IV y Fernando VII, además del breve reinado de José Bonaparte, y fueron agrupados siguiendo los criterios que el rey creyó oportunos.

La temática de la documentación es muy variada y de diversos orígenes, adecuándose a las preocupaciones e intereses del monarca. Hay que tener en cuenta que Fernando VII no tuvo reparos en obtener la documentación que creyese de utilidad para sus asuntos, sustrayéndola de sus entidades productoras (las Cortes, el Archivo del Ministerio de Hacienda, etc.); lo que posteriormente ocasionaría problemas y debates sobre quién debería albergar dicha documentación y nos llevaría al estado actual de la misma, dividida entre dos archivos.

Son en total 108 tomos encuadernados más dos índices, realizados con posterioridad, con el contenido de cada uno de los anteriores. Junto a estos 108 volúmenes encuadernados se halló más documentación, que luego sería "descartada" como perteneciente a dicha serie; siendo el único elemento que los relacionaba el lugar en el que se ubicaron ambos grupos documentales. Pero para simplificar esta investigación nos limitaremos a analizar sólo los volúmenes encuadernados.

En cuanto a su tipología es muy variada, pudiéndose hallar desde documentos oficiales y públicos: diarios de sesiones y borradores de actas secretas de las sesiones; decretos, órdenes, cédulas, etc. 


\subsection{OBJETIVOS}

El objetivo principal de este trabajo consiste en la identificación archivística de esta colección que constituye series facticias en los dos archivos que la custodian. Para llevarla a cabo se han fijado los siguientes objetivos específicos:

- Establecer, a grandes rasgos, la historia de la custodia o historia archivística. Analizar las vicisitudes de la custodia de la serie en los diferentes depósitos que la han albergado hasta su ubicación actual, detallando en cada momento quienes fueron los responsables de su conservación y las operaciones realizadas sobre los mismos.

- Explicar la actual disgregación de los documentos en dos instituciones archivísticas, como consecuencia de las decisiones adoptadas en distintos momentos históricos.

- Analizar el contenido de los documentos, destacando los temas más relevantes que en ellos se mencionan.

- Realizar de acuerdo con la Norma Internacional General de Descripción Archivística (ISAD-G) su descripción.

\subsection{METODOLOGÍA}

\subsubsection{METODOLOGÍA ARCHIVÍSTICA}

La metodología archivística aquí aplicada consiste en el método analítico que permite conocer los documentos generados por una institución y es el denominado procedimiento de identificación, soporte de todo el tratamiento archivístico (Mendo Carmona, 2004, p.36). La identificación puede entenderse desde un punto de vista maximalista, aplicado al fondo documental, o minimalista, a las agrupaciones documentales que los componen. En el caso que nos ocupa, los documentos objeto de estudio constituyen una serie facticia custodiada en dos archivos; a efectos de tratamiento archivístico, en este trabajo, es conveniente aplicar la metodología de la identificación de fondos ya que la naturaleza de los documentos, su agrupación y contenido la asemejan más a una colección facticia que a una serie archivística.

La identificación tiene un carácter analítico, y consiste en la investigación de las características de los dos elementos implicados en la génesis de la colección: el sujeto productor y el objeto producido. A partir de ella se cuenta con la información necesaria para realizar la descripción, que para Antonia Heredia "es el medio utilizado para obtener la información contenida en los documentos" (Heredia Herrera, 1987, p.216). La finalidad de la descripción archivística es identificar y explicar el contexto y el contenido de los documentos de archivo para hacerlos accesibles a los investigadores y al público en general. En este trabajo se 
han aplicado las normas internacionales de descripción y registros de autoridad, adoptadas por los organismos rectores de archivos en todo el mundo.

\subsubsection{ANÁLISIS DE CAMPO}

Para establecer la historia de la custodia de estos Papeles Reservados es necesario visitar el Archivo General de Palacio y el Archivo del Congreso de los Diputados.

En el Archivo de Palacio se consultó la información contenida en la serie Registro de Reales Órdenes Comunicadas al Archivo, en donde se encuentra la orden de traslado de los Papeles Reservados desde la Biblioteca Real al Archivo de Palacio. Por otra parte, en el registro de ingreso de fondos consta la fecha de entrada de la documentación y el volumen de la misma. Ambos datos proporcionan la constancia del ingreso de esta colección en el archivo y contribuyen a la reconstrucción de la historia archivística de la serie.

A continuación se procedió al estudio de los tomos de los Papeles Reservados allí custodiados y microfilmados, serie objeto de esta investigación que ha sido descrita y clasificada.

En el Archivo del Congreso de los Diputados esta colección está perfectamente estudiada en los índices que de dichos Papeles Reservados que se encuentran en el Archivo; además se puede seguir la pista localizando las sesiones de la comisión de Gobierno Interior donde se trató el periplo de esta colección, para lo cual se puede consultar las Actas de la Comisión de Gobierno Interior. La colección está digitalizada, descrita y clasificada en el sistema de información electrónica del Archivo.

\subsubsection{ANÁLISIS BIBLIOGRÁFICO}

La bibliografía existente sobre los Papeles Reservados de Fernando VII es, como se mencionó anteriormente, realmente escasa; en su mayoría no son más que citas o simples menciones secundarias en obras o artículos referidos a algún otro tema.

La primera referencia bibliográfica sobre el tema se encuentra en el Inventarioguía del Archivo de Palacio de Morterero Simón (Morterero Simón, 1977, p.21), quien dedica una amplia nota a pie de página a este tema, que incluye la Orden de 13 de mayo de 1842 para que se formase una comisión que revisara el "archivo reservado" y dispusiera el destino de dicha documentación. Resulta interesante comprobar que, en un principio, los destinos considerados para alojar esta serie facticia eran más variados que los dos a los que finalmente llegaron, dependiendo del origen o temática de los distintos documentos, militar, de hacienda, etc.

La otra lectura indispensable para la realización de este trabajo es, sin duda, el Derecho parlamentario español de Fernández Martín (Fernández Martín, 1900, p. 226-258. Esta obra hace un repaso histórico de los avatares políticos de las Cortes 
de España a través de los decretos, bandos, providencias y otras disposiciones normativas. En su tercer tomo, correspondiente a los años entre 1814 y 1820 , el autor dedica un capítulo de su obra al "archivo reservado" de Fernando VII, detallando el descubrimiento del mismo, así como los principales acontecimientos relacionados con dicha serie hasta su devolución por parte del Archivo del Congreso al de Palacio durante el reinado de Alfonso XII.

Para conocer la situación actual de los Papeles Reservados en el Archivo del Congreso y el proceso de digitalización de los mismos, que tuvo lugar en el año 2000, se consultó un artículo de Nadia Villarejo Sánchez (Villarejo Sánchez, 2006, p. 589-602) publicado en la Revista Española de Documentación Científica. Éste trata sobre los proyectos de digitalización de varios fondos del Archivo histórico del Congreso de los Diputados, describiendo brevemente el proceso realizado en cada uno.

En este artículo, la autora, describe como en el año 2000, en orden de preservar y proteger los originales contra daños derivados del uso y reproducción de los mismos, el Archivo del Congreso de los Diputados decidió digitalizar gran parte de sus fondos documentales más antiguos, mejorando, a su vez, el acceso informático a los mismos.

Con la serie que nos compete, se procedió al desencuadernado de los volúmenes originales, a su limpieza y restauración para, a continuación, guardarlos en un soporte neutro.

Una vez digitalizados los documentos, unas 5000 páginas aproximadamente, la información se incorporó a una base de datos.

\section{HISTORIA ARCHIVÍSTICA}

Durante la regencia de la reina María Cristina y con Espartero como presidente del Consejo se dictaron en el año 1840 dos decretos por los que se disponía que se formase una comisión para examinar e inventariar algunas posesiones de la Casa Real y todo lo perteneciente al patrimonio de la Corona. Cumplido este objetivo, la comisión informó sobre el descubrimiento, en 1842, de unos volúmenes encuadernados que llevaban por nombre Papeles Reservados en una de las estanterías de la biblioteca particular del difunto rey Fernando VII, situada en el que fuera su despacho. Estos volúmenes fueron guardados en cuatro cajas para, a continuación, ser inventariados por la misma comisión.

Una vez acabada esta tarea, se dividió la documentación en dos grandes grupos: el primero, comprendido por los 108 volúmenes encuadernados con tejuelo, denominados Papeles Reservados; y un segundo grupo, formado por diversa documentación que no disponía de ninguna indicación sobre su relación con los volúmenes antes mencionados, a excepción de compartir la misma balda en la biblioteca del fallecido monarca. 
Al ver que las indicaciones y anotaciones que figuraban en los volúmenes encuadernados fueron hechas por el propio Fernando VII, dedujeron con facilidad que había sido éste el artífice de la reunión y organización de la documentación.

En 1842 se presentó al ministro de Estado un inventario de los libros y papeles, quedando guardados en cuatro cajas en la Biblioteca Real y no vuelve a hablarse de ellos hasta siete años después.

En uno de los registros consultados para esta investigación, concretamente en uno de reales órdenes comunicadas al archivo, hay una comunicación copiada que envía el bibliotecario del rey al director del Archivo de Palacio, Tomás Zaragoza:

"He dado cuenta al Rey N. Sr. de la comunicación de V. de 19 del mes actual [septiembre] referente á los papeles reservados que encerrados en cuatro arcas ecsisten en la Biblioteca particular de S.M. á otros que no tienen aquel caracter... y enterado S. M. y apreciado el celo manifestado por $V$. ha tenido bien mandar = $1^{\circ}$ Que los papeles reservados se pasen al Archivo gral. del cargo de V. teniéndolos á disposición de S.M. para que puedan ser utiles al Real Servicio"1.

Seguido esto por la Real Orden de 22 de Septiembre de 1849 para trasladar los mismos, más o menos con las mismas palabras utilizadas por el bibliotecario mayor.

El ingreso de los Papeles al archivo se hizo efectivo, como podemos comprobar en los registros de entrada de documentos, el 27 de septiembre de 1849.

"Cuatro arcas con cerraduras y candados que contienen varios papeles reservados que se hallaban en el cuarto que fue despacho del Sr. Rei D. Fernando $7^{\circ}$ y que se formó inventario por la Comisión nombrada por el Gobierno en 1840 para entender en los respectivos a los bienes de S. M. y A. y cuyas llaves de las espresadas arcas están en el Archivo de la Real Casa. ${ }^{\prime 2}$

Allí se creó una sección especial con el nombre de Archivo Reservado de Fernando VII que fue colocada en una de las galerías subterráneas de Palacio Real, en la pieza de títulos de propiedad, aunque luego se trasladarían al despacho del archivero, quedando reflejado en el mismo registrto mediante una nota marginal.

Durante años los Papeles Reservados permanecieron en calma, al menos es lo que se puede deducir a partir de la nula mención a los mismos en los libros de registro.

Parte de esos volúmenes estaban compuestos por documentación parlamentaria que durante mucho tiempo fue buscada por investigadores y otras personalidades, llegando a sospecharse que se hallaba depositada en Palacio. Enterados de esto en

\footnotetext{
${ }^{1}$ Archivo General de Palacio Real. Registros Sig 5711, pág. 149.

${ }^{2}$ Archivo General de Palacio Real. Registros Sig 740, pág. 355.
} 
la Comisión de Gobierno Interior del Congreso de los Diputados, se solicitó a la Casa Real, por entonces bajo control de Amadeo I de Saboya, que se permitiese la consulta de los mismos. Esta solicitud fue concedida, aunque al parecer había una orden reservada para que se impidiese tal consulta mediante diferentes pretextos.

Finalmente, con la proclamación de la República, en 1873, el interés por esta serie facticia se reaviva y como consecuencia de ello en marzo de ese año se nombra una comisión cuyo cometido era revisar los documentos que deberían custodiarse en el Archivo de las Cortes. El resultado de esta operación fue el traslado de los Papeles al Palacio del Congreso de los Diputados el 3 de Abril de 1873. Así lo recoge el Registro copiador de reales órdenes comunicadas al archivo por Mayordomía Mayor:

"Delegación del Gobierno de la República para la Dirección general del Patrimonio que fué últimamente de la Corona ... Con esta fecha digo a los Sres. de la Comisión nombrada por la Asamblea para revisar los Archivos público y secreto de la suprimida Casa Real ... conforme con la proposición aprobada por aquel alto cuerpo en 11 de mayo del pasado ha acordado se trasladen al referido Archivo de la Asamblea los 108 tomos y legajos que constituyen el archivo reservado haciéndose la entrega al Bibliotecario de aquella..." ${ }^{\prime 3}$

Así fue como los Papeles Reservados pasaron a albergarse en el Archivo del Congreso de los Diputados, en 1873.

La situación política volvió a dar un vuelco con la restauración de la Monarquía constitucional, con Alfonso XII como rey. Esto supuso que se devolviesen a la Corona palacios, bienes, etc., así como los archivos que estuviesen bajo dependencias del Estado deberían ser devueltos a la Casa Real. Sin embargo, había documentación en los Papeles Reservados que era claramente de origen parlamentario y cuya propiedad pertenecía sin duda a las Cortes; de modo que se estableció un reparto de la serie: 44 volúmenes más unos cuántos folios desglosados se quedarían en el Archivo del Congreso de los Diputados, y los 64 volúmenes restantes regresarían al Archivo General de Palacio, era marzo de 1875.

\section{ANÁLISIS TEMÁTICO DEL CONTENIDO DE LOS PAPELES RESERVADOS}

En este apartado se analizará el contenido de los Papeles Reservados de Fernando VII, considerándolos como un fondo, independientemente del lugar en donde se encuentren depositados.

\footnotetext{
${ }^{3}$ Archivo General de Palacio Real. Registros Sig 5713, pág 60-61.
} 
Se trata de un análisis no pormenorizado de los mismos que busca más servir de orientación a futuros investigadores interesados en el tema que detallar uno a uno los documentos albergados. Para que resulte más sencillo de captar la variedad de temas tratados en los volúmenes encuadernados, se ha optado por presentarlos siguiendo una cronología de reinados, dejándose constancia de la signatura en dónde pueden ser localizados dichos tomos.

Carlos III

Cronológicamente, la primera documentación que debemos mencionar es una colección de cartas, cinco en total, del Conde de Aranda ${ }^{4}$, que datan del reinado de Carlos III.

El Conde de Aranda fue el gran rival de Floridablanca y ocuparía luego el puesto de secretario de Estado, en 1792, ya durante el reinado de Carlos IV. Era el líder del llamado "partido aragonés".

La conexión entre Pedro Pablo Abarca de Bolea, décimo Conde de Aranda, y Fernando VII se produjo a través de sus seguidores políticos, y es que, decapitado el rey Luis XVI en la vecina Francia, el Conde de Aranda cayó en desgracia debido al apoyo que había dado la Asamblea francesa, perdiendo su cargo y siendo reemplazado por Manuel Godoy.

Los miembros del partido aragonés se convirtieron entonces en acérrimos detractores del joven valido extremeño, encontrando en Fernando VII un líder para su causa. Pasarían a ser conocidos como el "partido fernandino".

\section{Carlos IV}

Continuando con esta línea cronológica, el siguiente reinado al que hacen referencia estos Papeles es el de Carlos IV, padre del por entonces Príncipe de Asturias.

En este período de tiempo, que coincidió en gran parte con la juventud del príncipe, hay un único tema que preocupa al futuro monarca de España: Manuel Godoy, quien acaparaba casi todo el odio del príncipe heredero, fruto de su natural desconfianza y alentada por varios allegados y sirvientes.

El mayor volumen de documentación, siete de los tomos encuadernados ${ }^{5}$, corresponde a correspondencia entre Godoy y miembros de la Casa Real, principalmente con la reina María Luisa.

A su vez, hay unos tomos dedicados a la correspondencia de Godoy con otros personajes sobre distintos temas políticos ${ }^{6}$ y uno dedicado a su documentación biográfica $^{7}$ : nacimiento, bautismo, nombramientos, condecoraciones, etc., junto

\footnotetext{
${ }^{4}$ Archivo General de Palacio (AGP). T. 108.

${ }^{5}$ AGP. T. 93-99.

${ }^{6}$ AGP. T. $100-102$ y 105.

${ }^{7}$ AGP. T. 104.
} 
con correspondencia y documentos relativos a su matrimonio con María Teresa de Borbón y Villabriga ${ }^{8}$.

También destacan los tomos primero y segundo, que abarcan el proceso de la llamada Conspiración de El Escorial, en la cual Fernando y otros personajes intentaron apartar a Godoy del gobierno y los reyes. Como sabemos, la conspiración fue delatada por un anónimo y abortada al encontrar el mismo Carlos IV papeles incriminatorios en las habitaciones del príncipe.

\section{José I}

A continuación viene el breve paréntesis en el reinado de los borbones en España que tuvo lugar durante la invasión francesa y la posterior imposición en el trono de José Bonaparte.

La documentación correspondiente a este período podría dividirse en tres temas principales. El primero, referido a la Constitución de Bayona ${ }^{9}$, que fue, en palabras de Fernández Sarasola, "el primer texto constitucional español, a pesar de que este lugar suele asignarse a la Constitución de Cádiz de 1812. El Estatuto fue una Carta Otorgada, a través de la cual Napoleón trató de institucionalizar un régimen autoritario, pero con un reconocimiento básico de libertades. Aunque el modelo de halla en el constitucionalismo napoleónico (Constitución francesa del año VIII, y textos napoleónicos de Westfalia, Nápoles y Holanda), la participación de una Asamblea de notables españoles sirvió para introducir unas leves particularidades al texto original, no presentes en otros documentos de Bonaparte, y entre los que destacan el papel más relevante que se otorgó a las Corte" (Fernández Sarasola, 2006, p. 89).

En este apartado se incluyen las relaciones de personas que fueron invitadas a Bayona, se presupone que eran afines a los franceses y los juramentes a dicha Constitución.

Un segundo apartado dedicado a diferentes asuntos de gobierno ${ }^{10}$; en donde se recogen las distintas actas de sesiones del Consejo de Ministros y del Consejo privado de José I, índices de expedientes, decretos, órdenes que tuvieron lugar en esta época, etc.

Y por último, y quizás el más importante en cuánto a las futuras acciones represivas de Fernando, podemos destacar un apartado sobre los afrancesados ${ }^{11}$. Los afrancesados, como sabemos, eran los españoles que juraron fidelidad a José I, ya fuese por interés personal o por la creencia en que el cambio de dinastía redundaría en la modernización de España.

\footnotetext{
${ }^{8}$ AGP. T. 103.

${ }^{9}$ Archivo del Congreso de los Diputados. (ACD) T. 3-4.

${ }^{10}$ AGP. T. 5-6 y 9.

${ }^{11}$ AGP. T. 6-10.
} 
El sistema político que defendieron se materializó en la Asamblea de Bayona y en el Estatuto aprobado en esa ciudad, mediante los cuales pretendieron volver a un sistema más moderno, aunque sin llegar al liberalismo radical de posiciones más extremas.

Defendieron medidas económicas innovadoras y claramente reformistas como la supresión de las aduanas interiores, la abolición del sistema señorial y de los mayorazgos y los privilegios de la nobleza y el clero.

Se encuentran aquí las listas de españoles que juraron fidelidad al "Rey intruso", así como aquellos que fueron distinguidos por parte del mismo.

Fernando VII

Las tropas francesas son derrotadas y, tras firmar el Tratado de Valençay, Fernando VII vuelve a España. Sin embargo no todo era como él lo había dejado. Cádiz.

Así, el primer asunto de interés para Fernando en este período son las Cortes de

Las Cortes de Cádiz se reunieron durante la Guerra de Independencia y dieron comienzo con su obra a la Revolución liberal en España aprovechando el vacío de poder. Se propusieron crear un marco legal que permitiera pasar de una sociedad estamental a una liberal y acabar con el Antiguo Régimen. Los diputados fueron convocados a Cortes en Cádiz por el Consejo de Regencia, a quien la Junta Suprema Central, viéndose incapaz de dirigir la guerra, traspasó sus poderes a comienzos de 1810. Muchas provincias ocupadas por los franceses no pudieron enviar representantes y buscaron suplentes en Cádiz.

Históricamente es uno de los asuntos más importantes debido al cambio que se produjo en la sociedad española. Se recogen copias y originales de las sesiones secretas de las Cortes, que tuvieron lugar entre 1810 y $1814^{12}$.

En el tomo 25 se encuentra un ejemplar original de la Constitución de 1812 (uno de los dos originales manuscritos, este sin encuadernar seguramente el del Consejo de Regencia; el otro manuscrito encuadernado en terciopelo rojo se encuentra en la caja fuerte del Archivo del Congreso de los Diputados), así como los documentos sobre la exclusión de los infantes Francisco de Paula y la gran duquesa de Luca, María Luisa; y en el tomo 52 un expediente de 1814 sobre la Constitución secreta.

El siguiente apartado es más pequeño en cuánto a volumen, se trata de la correspondencia entre los intermediarios de Fernando VII y sus padres, asentados en Roma. Los principales interlocutores fueron Pedro Ceballos y José Miguel de Carvajal-Vargas, Duque de San Carlos.

En este punto, pasaríamos a tratar otro tema, que podría denominarse con un nombre quizás demasiado genérico, el de los liberales. Y es que, restaurada la monarquía absoluta en 1814, Fernando VII se dispuso a perseguir y castigar a

\footnotetext{
${ }^{12}$ ACD. T. 26-34.
} 
aquellos que habían participado de algún modo en el proyecto de constitucionalidad del reino.

En los tomos 14 y 15 podemos encontrar listas, informes, notas y otra documentación sobre asuntos políticos y conducta política de varios sujetos.

Una causa contra el llamado Cojo de Málaga ${ }^{13}$, fechada en 1814, quien sin ser un personaje relevante en la sociedad (era sastre) pareció despertar insospechadamente el interés del monarca.

Pero Fernando debería hacer frente a otro revés en su atribulado reinado con el levantamiento encabezado por Rafael del Riego, viéndose obligado a jurar la Constitución. Llegamos al Trienio constitucional (1820-1823).

La documentación de este período trata sobre las juntas territoriales y, más abundantemente, sobre las Cortes. El tipo documental es muy variado, destacando el acta original de la jura del Rey a la Constitución ${ }^{14}$, órdenes y decretos promulgados por las mismas ${ }^{15}$, y el curioso caso del cura de Vinuesa ${ }^{16}$.

Casi todos los asuntos de gobierno que tuvieron lugar en esta época están reflejados en este apartado: asuntos militares, económicos, relaciones internacionales, etc.

Uno de los asuntos que más preocupaba a Fernando VII, como se puede deducir del gran volumen de documentación recopilada, era la masonería ${ }^{17}$.

El régimen absolutista de Fernando VII se orientó, como ya hemos visto, de una manera decidida contra el constitucionalismo, el liberalismo y la masonería. Según J. J. Morales Ruiz,(Morales Ruiz, 2003) en la España del siglo XVIII la presencia de logias masónicas era pequeña e intrascendental, sin embargo, con la llegada al trono español de José Bonaparte esta situación cambiaría. Napoleón propició la creación de logias masónicas en todo su imperio, utilizándolas como un instrumento político favorable a sus propios intereses. En 1809, a la vez que fueron suprimidas la Inquisición y algunas órdenes religiosas, nacieron diversas logias masónicas que pertenecían al Gran Oriente de Francia y estaban integradas casi exclusivamente por miembros del ejército napoleónico. La participación de españoles, la mayoría de ellos afrancesados, se inició de una manera definitiva con la creación de siete logias madrileñas y dos logias manchegas. Estas logias fueron el primer núcleo organizado de la masonería, y constituyeron la Gran Logia Nacional de España; aunque fueron desapareciendo a medida que las tropas francesas abandonaban el territorio español en 1813.

El cambio fue drástico, si José I promovió la creación de logias, Fernando las persiguió con saña. Este movimiento represivo se acentuó a partir de enero de

\footnotetext{
${ }^{13}$ ACD. T. 52.

${ }^{14}$ ACD. T. 60.

${ }^{15}$ ACD. T. 46 y 49.

${ }^{16}$ AGP. T. 23.

${ }^{17}$ AGP. T. $17-20$ y 66-67.
} 
1815 al restablecerse la Inquisición y promulgarse un edicto de Fernando que prohibía y condenaba la masonería. La policía y la Inquisición colaboraban estrechamente en la persecución contra los masones, algunos de los cuales se presentaron voluntariamente ante el Santo Oficio, otros fueron denunciados, y todos los que pudieron emprendieron el exilio.

Sin embargo, con el pronunciamiento de Riego se restablecieron las libertades políticas y de nuevo recobró vigencia la masonería española; pero esto no duró mucho y en 1824 Fernando VII logró derribar el régimen constitucional. En el exilio, masones, comuneros y carbonarios ahondaron todavía más sus divisiones y querellas. En España, mientras tanto, abundaron los escritos antimasónicos y se obligaba a todos aquellos que deseaban ejercer un empleo público, fueran militares o civiles, a realizar una declaración bajo juramento de no haber pertenecido a ninguna logia o asociación secreta.

Podemos encontrar varios informes y expedientes, muchos de ellos redactados por la Inquisición, de personas pertenecientes o sospechosas de pertenecer a distintas logias. Aquí destaca especialmente el expediente formado contra el Teniente Juan Van Halen ${ }^{18}$.

Uno de los asuntos más relevantes en el reinado de Fernando VII, y para la Historia de España, fue la situación en las colonias americanas y sus ansias emancipadoras. Se pueden consultar algunos panfletos sueltos impresos en Buenos Aires y Montevideo ${ }^{19}$. La documentación relativa a Cuba, que data de 1829, ocupa un volumen entero, mientras que en el tomo 23 se pueden encontrar papeles que hacen referencia a Nueva España (México) etc.

En 1823 las tropas de la Santa Alianza, comandadas por el Duque de Angulema, reestablecieron a Fernando VII como monarca absoluto de España, dando comienzo así a la Ominosa década.

Una vez más, la documentación aquí reunida es muy variada, tratando temas como los asuntos de gobierno y relaciones exteriores, correspondencia con el general Elío y asuntos relacionados con la llamada Regencia de Urgel, etc.

Dos volúmenes hacen referencia a distintos viajes de los reyes. Uno a Sevilla en 1823, y el otro a Cataluña en $1829^{20}$.

Este último fue motivado por una revuelta que estalló en 1827, protagonizada por realistas puros o intransigentes que acusaban al rey y a sus ministros de ciertas veleidades liberales. La sublevación, conocida como la guerra de los agraviados, estaba protagonizada por militares, clérigos y campesinos que habían luchado contra el Gobierno del trienio y se creían poco recompensados en sus esfuerzos. Abogaban por un absolutismo más extremista, y ya comenzaban a apoyar al

\footnotetext{
${ }^{18}$ AGP. T. 18.

${ }^{19}$ AGP. T. 14, 23 y 85.

${ }^{20}$ AGP. T. 69 y 85 respectivamente.
} 
hermano del rey, Carlos, como el futuro nuevo monarca. Sin duda esta guerra era ya la antesala de las posteriores guerras carlistas.

Fue en Cataluña donde la insurrección prendió con especial virulencia, y allí se dirigió el rey Fernando VII junto con su ejército, comandado por Teniente General Carlos d'Espagne, Conde de España. Aunque éste simpatizaba ideológicamente con los insurrectos, no dudó en reprimirles a sangre y fuego y ejecutar a sus principales cabecillas, acabando así en pocos meses con la sublevación.

En cuanto a los ya mencionados asuntos de gobierno, quizás valga la pena destacar el Código de Comercio presentado por Pedro Sainz de Andino en 1829 (t. 83), así como otra documentación política y económica tratada por él ${ }^{21}$.

Para concluir, no deja de sorprender un volumen dedicado a Cristóbal Colón, con instrucciones del mismo a sus colaboradores, inventarios de joyas y otros objetos recibidos por él mismo, así como capitulaciones del los Reyes Católicos en su favor ${ }^{22}$.

Y para finalizar este análisis, cabe mencionar dos volúmenes que contienen una colección de poesías ${ }^{23}$ escritas por la reina María Josefa Amelia de Sajonia, que podrían dividirse en dos grupos: las primeras 300 páginas están compuestas por oraciones para distintos momentos de la vida diaria: para antes y después de comulgar, por los enemigos, oración a San Joaquín, canción del santísimo sacramento, canción al "dulcísimo nombre de Jesús".

El segundo grupo versa sobre la vida del Rey Fernando III, también en tono religioso; son 17 cánticos en poco más de 250 páginas.

Se recogen además otros escritos ${ }^{24}$ de la segunda mujer de Fernando VII, donde también se pueden diferenciar dos grupos: las primeras 206 páginas contienen textos con matices políticos, "El enemigo generoso", "Fruto temprano de la buena educación", "El verdadero valor no se prueba con delitos", etc. El segundo grupo está compuesto por poesías, canciones y cuentos sobre diferentes temas: recuerdos sobre el 2 de Mayo de 1808, sobre la muerte del cura Matías Vinuesa, a los desterrados por desafectos a la Constitución, etc. Son casi 300 folios.

\section{PROPUESTA DE DESCRIPCIÓN NORMALIZADA}

Esta propuesta de descripción del fondo se ha realizado según la Norma ISAD (G). Se centra básicamente en la distribución de los campos de descripción relevantes y no en ser exhaustiva.

\footnotetext{
${ }^{21}$ AGP. T. 83.

${ }^{22}$ AGP. T. 72.

${ }^{23}$ AGP. T. 91.

${ }^{24}$ AGP. T. 92.
} 


\section{A - IDENTIFICACIÓN}

\section{Código de referencia:}

ES. 28079. A.C.D./ 3./ PAPELES RESERVADOS DE FERNANDO VII (1808 1823) (Archivo del Congreso de los Diputados)

ES.AGP/1.1.1./Papeles Reservados (Archivo General de Palacio ${ }^{25}$ )

Título: Papeles Reservados de Fernando VII

Fecha(s): Siglo XVIII - 1833

Nivel de descripción: Serie

Volumen y soporte: 108 tomos encuadernados

\section{B. CONTEXTO}

Nombre(s) del/los productores: Fernando VII

Historia archivística ${ }^{26}$ :

En 1842 se informó del descubrimiento de unos volúmenes encuadernados que llevaban el título de Papeles Reservados, hallados en el despacho del difunto rey Fernando VII. En marzo de 1842 se presentó al ministro de Estado una notainventario de los libros y papeles. Sin embargo, los papeles permanecieron en el mismo sitio. El ingreso de los Papeles al archivo se hizo efectivo el 27 de septiembre de 1849. Allí se creó una sección especial con el nombre de Archivo Reservado de Fernando II que fue colocada en una de las galerías subterráneas de Palacio Real. Con la proclamación de la República se trasladan los Papeles al Palacio del Congreso de los Diputados, el 3 de Abril de 1873. Aunque esta situación dio un vuelco al restaurarse la monarquía en la persona de Alfonso XII, pasando todos los archivos que se encontraban bajo dependencia del Estado a ser administrados por la Casa Real. Sin embargo, dado que en los Papeles Reservados existían documentos cuya propiedad no podían disputarse a las Cortes, ya que su naturaleza demostraba que había sido sustraídos de sus archivos, el ministro de Hacienda, Pedro Salvatierra, determinó la devolución a Palacio previo desglose de los documentos parlamentarios.

Forma de ingreso: El 27 de septiembre de 1849 ingresa la serie en el Archivo General del Palacio Real, procedente del despacho del difunto rey Fernando VII.

\section{C - CONTENIDO Y ESTRUCTURA}

Alcance y contenido ${ }^{27}$ :

La serie está formada por documentación de diverso origen, situándose cronológicamente desde el reinado de Carlos III hasta la muerte de Fernando VII, aunque la gran mayoría de los documentos son relativos al reinado de este último.

\footnotetext{
${ }^{25}$ Aún no tienen código de referencia como tal.

${ }^{26}$ Para más información, ver el apartado 2 de este trabajo.

27 Información tomada de los tomos índices que existen sobre los Papeles Reservados
} 
TOMO 1 (1342 folios)

Contiene la Causa de El Escorial y está subdividido en once "piezas".

- Primera pieza: contiene las reales órdenes para la formación e instrucción de la causa.

- Segunda pieza: formada por los papeles hallados en el despacho del príncipe Fernando; una copia de la diligencia en presencia de los reyes; y los reales decretos por los cuales se mandó arrestar al príncipe heredero y su posterior puesta en libertad.

- Tercera pieza: declaraciones de varios imputados y listas de personas detenidas y puestas en libertad.

- Cuarta pieza: documentos relativos al arresto del Conde de Orgaz y otros; expedientes y declaraciones de varias personas relacionadas con el asunto.

- Quinta pieza: Confesiones de varios imputados.

- Sexta pieza: Entrega de autos del proceso a los detenidos, y real decreto por el que se ordena quemar los escritos de los abogados.

- Séptima pieza: Defensa de los detenidos y conclusión del fiscal

- Octava pieza: Sentencia de los jueces.

- Novena pieza: exposición del Marqués de Caballero ante el Rey; tres cartas y representaciones del fiscal, Don Simón Viegas, durante la causa; un testimonio del escribano de gobierno de Aranjuez que afirmaba que la Causa de El Escorial se halló en la papelera de Manuel Godoy; y oficios y minutas pertenecientes a la causa del Príncipe de la Paz que datan de 1818.

- Décima pieza: parte diario del gobernador del Consejo daba desde el sitio de San Lorenzo a la Corte, que se hallaba en Aranjuez.

- Undécima pieza: Cartas y oficios sobre el abono de gastos por la Comunidad de San Lorenzo sobre los jueces y órdenes para ser pagados por la Real Hacienda.

TOMO 2 (677 folios)

Dividido en doce "piezas", que contienen una copia de la Causa de El Escorial.

- Oficio de don Arias Mon, decano del Consejo de Castilla, a Bartolomé Muñoz para que hiciese una copia íntegra de cada una de las piezas que componen la Causa de El Escorial.

- Primera pieza (folios 2-46): copias certificadas de las reales órdenes y los juramentos hechos por la servidumbre de los reyes.

- Segunda pieza (folios 127-197): copia certificada de los documentos hallados en el despacho de Fernando, y sus declaraciones.

- Tercera pieza (folios 198-134): copia de las declaraciones recibidas por Domingo Fernández Campomanes y Andrés Romero Valdés.

- Cuarta pieza: contiene declaraciones varias de la causa.

- Quinta pieza: Más declaraciones, confesiones y ratificaciones.

- Sexta pieza: copia de la defensa de los detenidos y de la conclusión fiscal. 
- Séptima pieza: una copia de la entrega de autos a los abogados defensores.

- Octava pieza: copia de una solicitud de un tal Giraldo sobre la firma de un recibo.

- Novena pieza: una copia de la sentencia y la remisión de la misma por el gobierno del Consejo.

- Décima pieza (folios 566-599): copias de varios documentos, como el testimonio del escribano de gobierno de Aranjuez mencionado en la novena pieza del tomo anterior, exposición del Marqués de Cavallero ante Carlos IV, etc.

- Undécima pieza (folios 600-610): copia certificada de las instrucciones para cifrar la correspondencia y cinco copias de la misma.

- Duodécima pieza (folios 617-677): minuta del borrador de un decreto declarando inocente al príncipe Fernando; borrador de una exposición hecha por Viegas a Godoy; correspondencia de Viegas con gente relacionada con al causa; etc.

TOMO 3 (21 folios)

Contiene documentos relacionados con las Actas de la Junta de Bayona:

- Juramento del Ejército español en el Norte.

- Juramento de los consejos.

- Relación de españoles convocados a Bayona por Napoleón.

- Constitución original firmada por los asistentes a las juntas de Bayona.

- Juramentos de los consejeros de Estado, así como de los nobles y demás invitados ante la familia real.

- Una carta de agradecimiento dirigida al Rey por la constitución que dio al Reino de Nápoles.

- Decreto de Napoleón nombrando Rey de España a su hermano José; decreto de Carlos IV renunciando a su corona en favor de José Bonaparte; orden de proclamación de José Bonaparte como nuevo monarca de España y respuesta de las provincias españolas.

TOMO 4 (378 folios)

Contiene varios dictámenes sobre el proyecto de constitución discutido en Bayona.

TOMO 5 (405 folios)

Actas del Consejo de Ministros que comprende sus sesiones desde el 24 de abril de 1811 hasta el 15 de julio del mismo año.

TOMO 6 (325 folios)

Contiene documentación de la etapa de gobierno de José I. Cartas del Duque de Santa Fé a la Secretaría de Estado sobre temas que podrían serle de interés (movimiento de ejércitos, distribución de socorros entre los refugiados españoles 
en Francia, etc.); un acta del Consejo privado sobre las joyas y alhajas pertenecientes a la Corona española; actas del Consejo privado desde el 16 de agosto de 1809 hasta el 5 del mayo de 1813.

TOMO 7 (1012 folios)

Listas de los españoles que obtuvieron la Cruz de la Orden Real de España, vulgarmente conocida como la Berenjena, creada por José I.

TOMO 8 (522 folios)

Más listas de personas que fueron nombradas caballeros de la en la orden arriba mencionada: obispos y clérigos, nobles, consejeros; así como listas de los pretendientes a las distintas distinciones que daba José I.

TOMO 9 (404 folios)

Relación de ministros y empleados del Consejo de la Real Hacienda que juraron fidelidad a José Bonaparte. Un índice general de los expedientes, decretos, órdenes y resoluciones expedidas durante el reinado de José I; y un compendio de decretos expedidos por el mismo Rey que se encontraban en el Archivo del Ministerio de Hacienda.

TOMO 10 (43 folios)

Más relaciones de adeptos al rey José Bonaparte: aquellos que lo siguieron a Valencia, con nombres, empleo y sueldos; una lista de empleados del Ministerio de Hacienda sobre los que se desconoce su afinidad; empleados civiles y nobles que siguieron al ejército francés; una relación de terrenos vendidos durante el reinado de José I, así como una de los bienes nacionales vendidos en subasta.

TOMO 11 (625 folios)

Causa formada por las Cortes Generales y extraordinarias, en 1811, a los miembros del Consejo de Castilla: Colón, Lardizabal, Riega, Conde de Pinar, Torres, Martínez Villela, González Carrillo, Larrumbide, Moyano, Duque de Estrada, Fernández Campomanes, Lasauca, Arjona y Arias- Prada por una discusión sobre unos artículos de la Constitución que se estaba discutiendo. En el folio 527 de este mismo tomo se halla la sentencia por la cuál se los declara "libres y exentos de toda culpa".

TOMO 12 (884 folios)

Documentación sobre una causa formada a los diputados de las Cortes en 1814, por atentar contra la soberanía de Fernando VII y sus poderes. Una lista de los diputados que firmaron el acta correspondiente al decreto de 2 de febrero de 1814 . 
TOMO 13 (831 folios)

Contiene el expediente general sobre la amnistía de 1817.

\section{TOMO 14 (291 folios)}

Documentación variada: informe de Saavedra sobre la Junta de Sevilla; estado de los ejércitos en 1814; copia de la resolución de 31 de agosto sobre los correos de gabinete; más listas de adeptos a José Bonaparte, esta vez se trata de empleados en rentas en Salamanca y que aún conservan su puesto, y los empleados de la villa de Madrid que sirvieron al monarca francés; listas de personas que tienen acceso a Palacio, de individuos de guardarropa "purificados", etc.; correspondencia variada; La prensa Argentina un impreso de Buenos Aires en contra de la soberanía española, una proclama en el mismo sentido por el Cabildo e intendente de Montevideo; una copia del decreto enviado al Consejo por Felipe $\mathrm{V}$ renunciando a la Corona en favor de Luis I y otra copia de una escrita al mismo; plan de campaña realizado por Juan Ozil y dirigido a Fernando VII el 21 de junio de 1815.

\section{TOMO 15 (834 folios)}

Carta del Marqués de Palacio, Pedro de Palacios y Santibáñez, del 15 de enero de 1815, al Rey para llamarle la atención sobre la conducta del general Joaquín Blake, el inspector Pires y el embajador de Francia; un par de cartas de Campo Sagrado desde Barcelona, la primera es un informe sobre personas que obtuvieron magistraturas en el Reino de Aragón y que data del 25 de enero de 1818, y la segunda, otro informe sobre el reconocimiento de pasaportes y arresto del Duque de Angulema, fechada el 22 de abril de 1818; copias de cartas escritas por Fernando VII, una al Papa y dos a sus padres; más correspondencia: de Francisco de Beránger, Conde de Abisbal, al Rey, de José Palafox sobre un confidente enviado a Francia, de Eguía desde Valladolid, del general Elío desde Valencia, de Castaños desde Barcelona, etc.; lista de personas que tomaron las armas para defender al Rey; papeles varios de la Logia de Santa Julia; índices de libros existentes en el Depósito General de Secuestros procedentes de distintas personas que escaparon junto a José Bonaparte; informes sobre la policía, expediente general sobre seguridad pública y su reglamento.

\section{TOMO 16 (513 folios)}

Dictamen del Duque de Montemar sobre las Cortes, en 1814; defensa y acusación fiscal del general Elío.

\section{TOMO 17}

Expediente sobre el descubrimiento de varias logias, con su índice de documentos que componen dicho expediente y personas relacionadas con las mismas. El índice consta de dos columnas, a la izquierda figura el título y/o resumen del documento, y a la izquierda los nombres de las personas que quedan 
"comprendidas" como masones... El expediente de este tomo está formado por 137 documentos.

TOMO 18

Más documentación sobre logias. Expediente formado sobre el encarcelamiento del teniente coronel Juan Van Halen, capitán del regimiento de Cazadores de Madrid y otros oficiales del Ejército; y el nombramiento de Luis García para la formación de la causa "reservadísima". Al igual que el tomo anterior, cuenta con un índice de documentos que conforman el expediente, a dos columnas, una para el título del documento en cuestión y otra para el nombre de los masones. El expediente está formado por 66 documentos.

Siguen los procesados por pertenecer a logias. Expediente formado sobre el envío a prisión de Antonio María del Valle y José María González, capitanes de Infantería, y a Juan Abascal, administrador de Correos en Granada. El expediente cuenta con 144 documentos.

Arresto de José María de Torrijos, coronel del regimiento de Lorena; Matías Moñino, sargento mayor de Artillería y otros oficiales. Expediente formado por 177 documentos.

Expediente sobre la averiguación de una logia masónica en Mallorca. Sigue con la numeración empezada en el expediente anterior; va desde el documento 178 hasta el 196.

Expediente formado por el encarcelamiento del oidor Juan Romero Alpuente y José Aramburu, capitán del regimiento de Lorena. Expediente formado por 53 documentos.

TOMO 19

Expediente de prisión de Francisco Carbonell, teniente retirado; Manuel Muñoz, capitán de Ingenieros; Carlos Martín y José Letamendi, tenientes del regimiento de la Reina; José Cardenas, alférez de Húsares españoles y otros oficiales. Contiene 25 documentos.

Expediente creado por el encarcelamiento de José María Pinto, subteniente agregado del regimiento de Extremadura, y Antonio Fernández Feran, coronel de Infantería retirado. Incluye 17 documentos.

Expediente de prisión de Francisco Javier Istúriz. Contiene 32 documentos.

Ordenes de seguimiento y control del capitán de Caballería José Joaquín del Alonso y el abogado Simón de la Plaza por sospechar de su conducta. Formado por 15 documentos.

Diligencias practicadas para la detención de Pablo Ventades y Juan López Pinto, oficiales de Artillería. 25 documentos.

Expediente del Marqués de Campo Verde sobre su arresto en Granada por considerársele masón. Compuesto por 9 documentos. 
Expediente de prisión de Luis Benitibi y Cándido Huertas, tenientes de Infantería. Contiene 7 documentos.

Expediente de prisión del Conde de Almodovar, comandante de Artillería de Valencia; Ramón Miralles, comisionado del Crédito Público; Martín Serrano, Domingo Hernández, Juan Bautista Genovés, abogados; Joaquín Lazaeta; José Torrecilla, subteniente de Artillería y otros. Contiene 81 documentos.

Instancia de la Condesa de Almodovar en favor de su marido, informe del Tribunal y reales órdenes. 6 documentos.

Expediente de prisión de Ramón Miralles, comisionado del Crédito público de Valencia. Tiene 5 documentos.

Diligencias practicadas para la prisión de Diego Baeza, criado de Vicente Bertrán de Lis, como cómplice de la conspiración de Valencia, y reales órdenes para vigilar la conducta del último. 18 documentos.

Expediente de la puesta en libertad de Juan Manuel Calderón, preso en las cárceles de la Inquisición de Murcia. 12 documentos.

\section{TOMO 20}

Este tomo prosigue con los expedientes relativos a la masonería.

- $\quad$ Expediente sobre la detención de Juan Antonio Tejero y Carlos de la Cruz Pujalte, alférez de Caballería retirado. Contiene 3 documentos.

- Detención de Manuel Robles, conocido como José Pacheco Menache, y sus compañeros José López Durán y Antonio Martínez Vélez; y varios recursos de la Condesa de Benavente. Formado por 80 documentos.

- $\quad$ Expediente para que el capitán de Reales Guardias de Infantería pase a disposición del Tribunal del Santo Oficio. Son 5 documentos.

- Causa formada a Marcelino Vélez Villa, alcaide de las cárceles secretas del Tribunal del Santo Oficio, por la fuga de Van Halen. Contiene 19 documentos.

- Expediente de prisión de Isidoro Navarrete, teniente del regimiento de Infantería de Cantabria. Tiene 10 documentos.

- Expediente con consultas del Tribunal de la Inquisición y del fiscal Luis García sobre una causa "reservadísima" relacionada con Juan Van Halen y sus cómplices. Formado por 40 documentos.

- Solicitud de Pedro Fermín de Iriberri, brigadier y gobernador de Orihuela, de la Llave de Gentil Hombre. Son 3 documentos.

- Reales órdenes para que Antonio Calbo y su familia sean puestos en libertad y se le devuelvan algunas pertenencias. 20 documentos.

- Documentación confiscada en el resguardo de Bilbao y diligencias para evitar la entrada a España de "malos libros". Son 28 documentos. 
TOMO 21 (230 folios)

Contiene documentación variada: un par de decretos de la Junta Provisional de Gobierno de España e Indias; una proclama de la Junta Superior del Reino de Valencia a sus habitantes; partes militares de Palencia, listas de personas que han formado parte de distintas asociaciones liberales, un impreso con noticias oficiales de París, un impreso titulado Boletín del Mediodía.

\section{TOMO 22 (369 folios)}

Contiene distintos escritos de Gaspar Vigodet dirigidos a Fernando VII en 1818 y 1819, y algunas reales órdenes relativas al mismo; distintas exposiciones realizadas por arzobispos y otros eclesiásticos al Rey sobre diversos asuntos entre 1820 y 1822; una copia de una exposición de la Regencia de Urgel dirigida al Consejo de Verona; correspondencia variada; una exposición de la Regencia de Urgel a Fernando VII sobre sus responsabilidades de gobierno, fechada el 15 de agosto de 1822; un documento en el que varios miembros de la Corte le piden al Rey que deponga a varios ministros y que reconsidere su conducta en las Cortes extraordinarias, fechado el 14 de noviembre de 1321; más escritos de la Regencia de Urgel y, en especial, del Marqués de Mataflorida.

\section{TOMO 23 (666 folios)}

Contiene, entre otra, la siguiente documentación: una exposición de la Junta Provisional de Gobierno, de 18 de marzo de 1820, y otra de Francisco Ballesteros sobre la necesidad de formar un Ministerio favorable al régimen constitucional establecido, y algunos personajes recomendados para los distintos ministerios; más propuestas de consejeros de Estado hechas por las Cortes, recalcando la necesidad de que se hayan declarado afectos al sistema constitucional; una carta de Antonio Barata renunciando al Ministerio de Hacienda; correspondencia entre Fernando VII y Ramón López Pelegrin sobre distintos asuntos en donde puede apreciarse la desconfianza del Rey hacia los miembros de las Cortes; parte de Luis Balanzat sobre la derrota de las tropas realistas en Famarite; varias dimisiones a distintos ministerios: Martínez de la Rosa, Moscoso, Clemencin, Sierra Pambley, etc.; y una contestación de Fernando VII no admitiendo dichas renuncias, y posterior respuesta de los mismos personajes mostrando su voluntad de renunciar a sus cargos; una copia de las medidas de seguridad tomadas para proteger a Matías Vinuesa y parte del atentado cometido contra el mismo; un plan elaborado por López Pelegrin para la pacificación de los territorios del Virreinato de Nueva España y un escrito sobre la independencia de México; una lista de personas sospechosas que conviene alejar de la Corte; una carta de Carbajal, de 16 de noviembre de 1820, sobre su nombramiento como capitán general de Castilla La Nueva, y otra de Gaspar Vigodet resistiéndose a entregar el mando; correspondencia tensa entre Fernando VII y las Cortes sobre distintos asuntos; una exposición de la Diputación Permanente de Cortes, de 12 de junio de 1822, 
dirigida al Rey sobre la situación crítica que atraviesa la Nación y las medidas que deben tomarse para salvarla y respuesta del monarca.

TOMO 24 (517 folios)

Exposición de Francisco Ramón Eguía sobre su comportamiento y acciones durante la revolución realista contra el régimen constitucional; ídem de Ramón Chambo, Juan Sánchez Cisneros y Rafael Sampere; varios escritos dirigidos al Rey sobre el estado de la Nación, de los ministerios, del Consejo de Estado y la administración pública; etc.

El tema principal de los documentos que forman parte de este tomo es la vuelta de los realistas al poder, las acciones militares que llevaron a cabo las tropas leales a Fernando y la depuración de los miembros liberales de las entidades de gobierno.

TOMO 25 (384 folios)

Contiene documentos sobre la exclusión, por parte de las Cortes de 1812, de los infantes Francisco de Paula y la gran duquesa de Luca, María Luisa, para suceder al trono español, y la posterior derogación de esto por las mismas Cortes en 1820; y un original de la Constitución de 1812, firmada por los diputados de las Cortes de aquel año.

TOMOS 26 - 31 (1255 folios)

Todos ellos contienen las actas de las sesiones secretas de las Cortes generales, extraordinarias y ordinarias, desde 1810 a 1814.

TOMO 32 (972 folios)

Contiene dos legajos de los borradores de las actas arriba mencionadas.

TOMO 33 (830 folios)

Contiene dos cuadernos de actas de las sesiones de la Diputación permanente de Cortes desde el 9 de septiembre de 1813 hasta el 25 de febrero de 1814.

TOMO 34 (565 folios)

Contiene, entre otros, los siguientes documentos: un legajo que contiene las instrucciones de la Junta Central del Reino, en 1810, para las elecciones de diputados para las Cortes; un oficio del Ministerio de Gracia y Justicia, de 30 de septiembre de 1810, remitiendo a las Cortes unos ejemplares de una memoria de la regencia del Reino; supresión del ejercicio de de los empleos de los distintos Diputados de las Cortes, mientras estén en su cargo; un escrito del presbítero Blas Ostolaza y Ríos haciendo algunas sugerencias sobre distintas entidades gubernamentales; otra proposición, esta vez del Sr. Argüelles, para que se distribuya en la península el Diario de Cortes; más instrucciones para la elección de diputados, de Península y Ultramar, para las Cortes ordinarias de los años 1813 
y 1814; una proposición del Martínez de la Pedrera para que se hagan "demostraciones de júbilo" por la traslación de las Cortes a Madrid, y otras proposiciones de varios diputados para distintos asuntos de mayor o menor importancia; un expediente sobre algunas expresiones injuriosas dichas por el Conde de Vigo en sesión pública.

\section{TOMO 35 (754 folios)}

Contiene dos libros de actas de la Junta Provisional de Gobierno, nombrada el 9 de marzo de 1820, y los borradores de dichas actas.

TOMO 36

Contiene un legajo que contiene los expedientes despachados por la Junta Provisional de Gobierno desde su nacimiento hasta su final, con sus conclusiones dirigidas al Ministerio de Estado; otro legajo con documentación de la Junta Provisional relacionados con el Ministerio de Gracia y Justicia, el legajo comienza con un índice completo de los documentos incluidos.

TOMOS 37 y 38

Contienen dos legajos que incluyen documentación de la Junta Provisional relacionada con asuntos militares, el segundo, además, cuenta con un índice de los documentos incluidos en ambos.

TOMO 39

Más documentación de la Junta Provisional de Gobierno, esta vez relacionados con la Marina y Hacienda.

TOMO 40

Documentación de la Junta Provisional de Gobierno, que hace referencia al Ministerio de la Gobernación de la Península.

TOMO 41 (438 folios)

Contiene más documentación producida por la Junta Provisional de Gobierno y su correspondencia con las juntas de La Coruña, Oviedo, Zaragoza, Pamplona, Málaga, Barcelona, el Cabildo de Córdoba, distintos ayuntamientos, Cádiz, León, Valencia.

TOMO 42 (281 folios)

Contiene un expediente que incluye los trabajos de las juntas constituidas en San Fernando, La Coruña, Zaragoza y Pamplona, instaladas antes de saberse la noticia de que Fernando VII había jurado la Constitución, y el manifiesto original de la Junta Provisional de Madrid enviado a las Cortes, informando sobre sus actuaciones. 
TOMO 43 (190 folios)

Este tomo contiene las actas de la primera Diputación Permanente de las Cortes de 1820 , desde el 10 de noviembre de 1820 hasta el 25 de febrero de 1821.

\section{TOMO 44 (370 folios)}

Más actas de la Diputación Permanente, esta vez van desde el 1 de julio de 1821 hasta el 25 de febrero de 1822.

TOMO 45 (416 folios)

Otro libro con actas de la Diputación Permanente, entre el 1 de julio de 1822 hasta el 25 de febrero de 1823.

TOMO 46 (170 folios)

Contiene órdenes de la Diputación Permanente de las Cortes desde el 10 de noviembre de 1820 hasta el 24 de febrero de 1821.

TOMO 47 (138 folios)

Copias de las actas de la Diputación Permanente, desde el 25 de julio de junio de 1820 hasta el 28 de junio de 1821.

TOMO 48 (928 folios)

Contiene un legajo con las actas secretas de Cortes en borrador desde 1820 hasta 1823.

TOMO 49 (769 folios)

Más actas secretas de las Cortes, desde el 18 de enero de 1822 hasta el 1 de agosto de 1823; actas públicas de las Cortes desde el 11 de junio de 1823 hasta el 5 de agosto del mismo año; un legajo con actas públicas de las Cortes entre junio y agosto de 1823; un legajo con un registro de decretos de las Cortes extraordinarias de 1823.

TOMO 50 (869 folios)

Contiene: borrador de las actas de la Diputación Permanente de las Cortes entre 1820 y 1823; nombramiento de presidente, vicepresidentes y secretarios en las Cortes de 1820; una declaración de las Cortes para no admitir felicitaciones que no sean por escrito; solicitudes de diputados para obtener licencias temporales.

\section{TOMO 51 (574 folios)}

Contiene, entre otros, los siguientes documentos: una exposición de la Junta Nacional del Crédito Público; un reglamento que propone la misma Junta para la venta de fincas; una memoria del secretario del Despacho de Hacienda sobre el Crédito Público; un escrito de Pedro Delgado sobre rentas y recursos de la 
monarquía española; una memoria sobre la ruina de la Real Fábrica de Hoja de Lata, escrito por Vicente Perera; un informe de la Junta General de Ganaderos sobre la ganadería trashumante; una exposición de la Diputación Provincial de Navarra sobre el estado de esa región.

\section{TOMO 52 (485 folios)}

Contiene un expediente formado por la constitución secreta formada por las Cortes y otros documentos relacionados con ésta; un dictamen de la comisión de premios a favor de Pablo López, conocido como "el Cojo de Málaga", y la causa formada a éste en 1814.

\section{TOMO 53 (1125 folios)}

Contiene: Real Orden de 8 de noviembre de 1820 mandando cesar las sociedades y juntas patrióticas, y exposiciones de varias juntas patrióticas respondiendo a esto; un legajo sobre el permiso a los diputados para dar informes y promover en el gobierno asuntos respectivos a sus provincias; un expediente sobre el estado político de la Nación.

\section{TOMO 54 (754 folios)}

Tres empréstitos de la Comisión de Hacienda.

\section{TOMO 55 (1554 folios)}

Contiene, entre otros, los siguientes documentos: un expediente con un impreso de Juan José Marco del Pon sobre una cesión de dinero que hizo Miguel de la Grúa y Talamanca, Marqués de Branciforte, al rey José I; varios expedientes más con asuntos relativos a la Hacienda Pública, solicitud de pensiones y plazas, una memoria de Antonio Romea sobre un plan de contribuciones, y otra de Manuel Rodríguez para combatir el contrabando; un expediente del secretario del Despacho de Hacienda sobre la forma de abonarse las raciones devengadas por varios presidiarios desde 1815 a 1818 , y otro del mismo autor para fijar el precio del tabaco; un escrito de Pedro Berrocoso dirigido a las Cortes con un proyecto para la extinción de la deuda; un escrito de Tomas Moore remitido a las Cortes sobre derechos y aduanas; un escrito del Vizconde del Castillo de Almansa sobre simplificar el ramo de Hacienda; Antonio de Salas, alcalde de Ceuta, presenta un proyecto sobre sistemas de rentas y crédito público.

\section{TOMO 56 (487 folios)}

Contiene: propuesta de varios miembros de la milicia de Vila-Real sobre el reglamento de la misma, y otro escrito semejante pero de las milicias nacionales de Valencia, San Fernando, Oviedo, Medina del Campo, Valladolid y Málaga, y más documentación relacionada con las milicias; un oficio de la Secretaría de Estado manifestando que el Rey ha aceptado la dimisión de los secretarios de 
Estado: Manzanares, Osorio, Calatraba, Puente y Golfin; un escrito de la Diputación Permanente sobre la desigualdad que se nota en el pago de la dietas de los diputados; una orden de la misma para que se imprima el proyecto del código de procedimiento criminal; una relación de los porteros, celadores, mozos de oficio y maceros de las Cortes con la fecha en la que empezaron a servir en las mismas; un inventario de las alhajas que fueron robadas en el saqueo de Sevilla por las tropas francesas; un "legajo reservado" con "ocurrencias" entre el Rey y el Duque de Angulema, en septiembre de 1823; actas de las seis sesiones secretas de las Cortes extraordinarias con sus correspondientes minutas y correspondencia entre el Rey y el mencionado Duque.

\section{TOMO 57 (346 folios)}

Contiene diversa documentación relativa a las Cortes de 1823: oficios relativos a la traslación y pérdida de equipajes; minutas que hacen referencia a la continuación de las sesiones de las Cortes en Cádiz; nombramiento de diputados que han de formar parte de la Comisión de Cortes; actas de las sesiones de Cortes de los días 11 y 12 de junio de 1823; una lista de individuos de la milicia nacional de Madrid que debían incorporarse a sus batallones en León; un índice con todos los papeles pertenecientes a la secretaría, archivo y comisiones de las Cortes que se "salvaron en el río".

\section{TOMO 58 (379 folios)}

También formado por documentación de la etapa de las Cortes de 1823; contiene, entre otros, los siguientes documentos: dos exposiciones dirigidas a las Cortes por parte del visitador de la Audiencia Territorial de Canarias sobre una causa por conspiración; un oficio de Gracia y Justicia sobre presidiarios; un legajo que contiene los partes de salud del Rey entre los años 1820 y 1822.

\section{TOMO 59 (377 folios)}

Está formado por: un legajo con ejemplares impresos de la sesión de 11 de junio de 1823 sobre el traslado de Fernando VII a Cádiz desde Sevilla, y el nombramiento de una regencia interina; un legajo de la Diputación Permanente de las Cortes de 1823 sobre los negociados de Estado, Guerra y Marina que contiene: un expediente sobre si se tomaron las medidas convenientes para la defensa de la isla gaditana, varios nombramientos de despachos, un expediente sobre el mal estado de las torres de vigilancia de la provincia de Cartagena; una orden de Guerra sobre la organización de batallones en Tenerife, Canarias, Palma y otras islas; un libro de actas de la Comisión de Gobierno Interior, desde el 19 de junio hasta el 5 de agosto de 1823 . 
TOMO 60 (589 folios)

Contiene: un legajo con diecinueve decretos sancionados por el Rey en 1820; otro con doce leyes sancionadas por el mismo en 1821; otro con leyes sancionadas en 1822; tres oficios del Despacho de Hacienda al secretario de la Diputación Permanente sobre asuntos financieros; una carpeta con las partidas de bautismo de los infantes Juan Carlos María Isidro (n.15 de Mayo de 1822), Isabel Fernandina Josefa (n. 18 de Mayo de 1821), Francisco Asis María Fernando (n. 13 de mayo de 1822) y Enrique María Fernando Carlos (n. 17 de abril de 1823); un libro que contiene el juramento del rey Fernando VII en el Salón de las Cortes, el día 9 de Julio de 1820.

\section{TOMO 61 (327 folios)}

Este tomo está formado por un legajo que contiene las felicitaciones de varias corporaciones a las Cortes por su instalación. Empieza con un índice de las mismas.

\section{TOMO 62}

Contiene un legajo, numerado con el número 1, formado por documentación relacionada con un pleito entre el Cabildo de Lorca y el obispo de la Catedral de Cartagena.

\section{TOMO 63}

Otro legajo, esta vez con el número 2, con documentación sobre bulas detenidas y mercedes del cardenal Aguaviva; y un tercer legajo, con documentación sobre la muerte del papa Pio VI (un decreto expedido en consecuencia de esto, la publicación de la noticia en la Gaceta, etc.)

\section{TOMO 64}

Este tomo contiene dos legajos, que llevan los números 4 y 5 . El primero contiene un expediente formado con documentación generada al presentarse varias solicitudes de dispensa matrimonial; y el segundo que contiene un estado del número y clase de individuos de los cabildos, fábricas, parroquias y capellanías de la Diócesis de Valladolid.

\section{TOMO 65 (531 folios)}

Contiene un expediente con una causa formada al obispo de Córdoba sobre su conducta favorable al reinado de José Bonaparte; otro expediente de la Junta de Restablecimiento de los Jesuitas, formada por una real orden; y, según el inventario de los Papeles Reservados, debería haber una propuesta de diseño para levantar en Cádiz un monumento en memoria de la Constitución, pero que en realidad no se encuentra en el fondo. 


\section{TOMO 66 (129 folios)}

Un índice que contiene los sujetos que pertenecieron a sociedades secretas (y prohibidas), así como los oficiales del ejército que proclamaron la Constitución de 1812 .

\section{TOMO 67 (362 folios)}

Una lista con nombres de los militares que eran masones (p. 1-35); otra lista con militares pertenecientes a logias masónicas y otras sociedades secretas (p. 3670); otra lista con eclesiásticos que pertenecían a sociedades prohibidas (p. 71-80); más listas de gente que pertenecía, o se sospechaba que lo hacían, a sociedades secretas: letrados, empleados civiles, milicianos nacionales, lista alfabética de masones madrileños (p. 159-207); una historia de la masonería en España (p. 208214); un juramento que hacían los masones en Inglaterra (p. 283-284).

\section{TOMO 68 (129 folios)}

Contiene correspondencia original del capitán general de Valencia, Francisco Javier Elío, con el coronel Antonio Ronda sobre los sucesos de aquella ciudad hasta su fallecimiento. En total son 231 cartas.

\section{TOMO 69 (546 folios)}

Este tomo está compuesto por una especie de diario del viaje que hizo Fernando VII y su familia a Sevilla en 1823 . Son sesenta documentos numerados que dejan constancia de lo ocurrido durante el viaje y, además, se mencionan las ciudades y villas que atravesaron los reyes en su itinerario, mencionándose anécdotas de las mismas como su riqueza, fábricas, industria, etc. Va desde el 11 de febrero al 13 de noviembre, fecha en que los reyes regresaron a Madrid.

\section{TOMO 70 (389 folios)}

Contiene: un análisis del decreto de 4 de febrero de 1824 sobre la deuda pública; una exposición del Marqués de Almenara sobre un empréstito para el regimiento de París por 800 millones de reales y la respuesta a esto en forma de seis artículos con condiciones que debe cumplirse para ello, hay una nota marginal del propio Fernando VII que dice que si y sólo si se cumplen dichas condiciones se podrá acceder a tal préstamo; y diversos asuntos de gobierno relacionados con la economía.

\section{TOMO 71 (383 folios)}

Está formado por 57 documentos entre los que se encuentran: un comunicado cifrado del Gobierno constitucional dirigido a sus generales y tropas, fechado en mayo de 1823; una carta anónima fechada el 1 de junio de 1823 con un plan para impedir la entrada de los franceses en Andalucía; informes sobre la conducta de los magistrados de Sevilla dirigidos al comisionado regio, Antonio María Segovia, 
y varias cartas más entre Pedro Lafite y el mencionado comisionado regio de Andalucía sobre las tropas de Riego y Ballesteros; un escrito, con fecha de 31 de agosto de 1823, del capitán general Francisco Longa sobre el estado de los reinos de Valencia y Murcia, y con algunas sugerencias sobre distintos temas de gobierno (castigos para ladrones, prohibición de la entrada de arroz extranjero, etc.).

\section{TOMO 72 (226 folios)}

Contiene: Un extracto de la vida de Cristóbal Colón (folios 1-3), desde 1486 hasta 1493; unas instrucciones que dio el mismo Colón a Mosen Pedro Margarite en la Isla Isabela (folios 4-9), cuando fue a descubrir la tierra firme, el 9 de abril de 1484; una nota (folios 10-13) con la cantidad de oro y joyas recibidas por Colón en 1495; capitulaciones de los Reyes Católicos con Cristóbal Colón y mercedes concedidas a éste (folios 14-32); correspondencia entre Fernando VII y la Regencia de la Españas, de 1814, respecto a un tratado de paz con los franceses que el Gobierno provisional rechazó mientras el rey se encontrara en poder de estos, el intermediario fue el general Palafox; y otra carta de la citada Regencia, de marzo de 1814, al monarca informando a éste de la necesidad que jure la Constitución antes de recibir el traspaso de poderes; una carta de las Cortes, de 30 de abril de 1814, dirigida al Rey (ya en territorio español), procurando que éste se de prisa para dirigirse a las Cortes y empezar a gobernar "constitucionalmente"; un Decreto de octubre de 1816 por el que se relevaba de sus funciones a los liberales sentenciados por sus opiniones y/o escritos, y por el que se crea una junta que investigase más a fondo a los mismos; una traducción de una nota enviada desde Rusia el 15 de agosto de 1820 sobre los negocios con España y haciendo sugerencias sobre la "cicatrización" de la sociedad española para evitar la intromisión de reinos extranjeros; una exposición del Marqués de Sonora al rey Fernando, con fecha de 24 de abril de 1822, con una propuesta para establecer una nueva forma de administrar el Patrimonio Real; un extenso índice con los documentos del archivo de la Regencia de Urgel que contiene, entre otros, los siguientes papeles: correspondencia entre el Marqués de Mataflorida y el general Eguía, así como otros personajes como el vizconde de Boisset, Fermín Martín de Balmaseda, Pedro Podio, etc.; la proclama de la Regencia, de 15 de agosto, sobre su instalación y las primeras provincias que cayeron bajo su influencia; una relación de varias juntas, obispos y generales adeptos a la Regencia; correspondencia entre José Álvarez de Toledo y la Regencia de Urgel; una autorización de la Regencia para que el general Longa promueva un levantamiento en las provincias vascongadas; una orden del Duque de Angulema confinando a los miembros de la Regencia en distintos pueblos de Francia; y una especie de historia de la Regencia, en la cual se llama la atención sobre las persecuciones que sufrieron sus miembros por el general Eguía y sus partidarios. 


\section{TOMO 73}

Contiene unas doscientas relaciones de méritos de distintos magistrados.

TOMO 74

Más relaciones de méritos de magistrados, este tomo comprende desde la 201 a la 400.

TOMO 75

Siguen las relaciones de méritos de magistrados, va desde el 401 al 600.

\section{TOMO 76}

Más relaciones, desde la 601 a la 800 .

\section{TOMO 77}

Otras doscientas relaciones de méritos de magistrados, comprende desde el 801 a la 1000 .

\section{TOMO 78}

Contiene relaciones de méritos de magistrados, desde la 1001 a la 1200 .

TOMO 79

Y más relaciones de méritos de magistrados, va desde la 1201 a la 1432.

\section{TOMO 80}

Contiene 85 relaciones de méritos de magistrados de Ultramar, y 70 de los prebendados del mismo sitio. Además, cuenta con un índice con las relaciones comprendidas en los tomos anteriores (73 a 80 ).

\section{TOMO 81}

Contiene 34 listas sobre distintas personas: solicitantes de magistraturas en audiencias territoriales, en la regencia de la Audiencia territorial de Galicia, y en distintas adjudicaturas dispersas en el territorio español, listas de solicitantes de prebendas en iglesias de Lima, Guatemala, México, Cuba.

\section{TOMO 82}

Este tomo está formado por 17 listas con pretendientes a dos plazas de ministro en el Tribunal Supremo de Justicia, más solicitantes de distintas magistraturas y judicaturas; y un índice con las listas de méritos contenidas en este tomo.

TOMO 83 (254 folios)

Código de Comercio presentado por el fiscal del Consejo de Hacienda, Pedro Sáinz de Andino, ante el Rey el 26 de mayo de 1829 y aprobado por el mismo en día 30 del mismo mes. 
TOMO 84 (138 folios)

Un proyecto de Código de Comercio formado por la comisión especial creada el 11 de enero de 1828.

\section{TOMO 85 (352 folios)}

Contiene unas memorias de la isla de Cuba presentadas a Fernando VII por el coronel de Infantería Joaquín de Miranda, en julio de 1829; varios escritos con temas militares relacionados con dicha isla, y una memoria económico-política de la misma, así como un censo de su población en esa época.

TOMO 86 (256 folios)

Este tomo contiene un diario de viaje del desplazamiento del Rey desde el Real Sitio de San Lorenzo hasta la plaza de Tarragona en septiembre de 1827 y su regreso a Madrid en agosto de 1828.

TOMO 87 (185 folios)

Contiene la "Memoria histórica de la gloriosa expedición del Rey N. S. a Cataluña en 1827"

TOMO 88

Memoria de la conducta del Gobierno de España con respecto a Portugal, desde la muerte del rey Juan VI (1826) hasta la proclamación de Miguel I (1828).

TOMO 89 (482 folios)

Incluye una exposición de Pedro Sáinz de Andino al Rey sobre el estado del Reino, dividida en cinco secciones:

Sobre la administración de justicia civil y criminal.

Sobre la administración civil o pública del Reino.

Sobre la administración económica del mismo.

Sobre la organización del Ejército de Tierra y Mar.

Sobre la política exterior.

TOMO 90 (331 folios)

Contiene diferentes documentos relacionados con Pedro Sáinz de Andino entre 1828 y 1829: exposición sobre el proyecto de ley sobre recaudación y cobranza de las contribuciones reales, un informe legal sobre el derecho de extranjería, un informe legal sobre las islas mayor y menor del Guadalquivir y su conveniencia para cultivar en ellas y agregarlas al Patrimonio Real, etc.

TOMO 91

Contiene una colección de poesías escritas por la reina María Josefa Amelia de Sajonia, que podrían dividirse en dos grupos: las primeras 300 páginas están 
compuestas por oraciones para distintos momentos de la vida diaria: para antes y después de comulgar, por los enemigos (pág. 16), oración a San Joaquín, canción del santísimo sacramento, canción al "dulcísimo nombre de Jesús" (pág. 22).

El segundo grupo versa sobre la vida del Rey Fernando III, también en tono religioso; son 17 cánticos en poco más de 250 páginas.

\section{TOMO 92}

Contiene más escritos de la segunda mujer de Fernando VII, María Josefa Amalia; también se pueden diferenciar dos grupos: las primeras 206 páginas contienen textos con matices políticos, "El enemigo generoso" (pág. 34), "Fruto temprano de la buena educación" (pág. 38), "El verdadero valor no se prueba con delitos" (pág. 78).

$\mathrm{Y}$ el segundo grupo, está compuesto por poesías, canciones y cuentos sobre diferentes temas: recuerdos sobre el 2 de Mayo de 1808, sobre la muerte del cura Matías Vinuesa, a los desterrados por desafectos a la Constitución, etc. Son casi 300 folios.

\section{TOMO 93}

Tomo dedicado a la correspondencia entre los reyes Carlos IV y su mujer, María Luisa, y Manuel Godoy. Este tomo contiene cartas de los reyes dirigidas al Príncipe de la Paz entre 1799 (111 cartas) y 1800 (123 cartas).

\section{TOMO 94}

Contiene las cartas escritas por los reyes, María Luisa principalmente, a Godoy en el año 1801. Son 131 cartas en total.

\section{TOMO 95}

Contiene 75 cartas escritas por la reina María Luisa a Manuel Godoy, en el año 1802; y 160 correspondientes al año 1803.

\section{TOMO 96}

Más cartas de la reina dirigidas a Godoy; son 183 correspondientes al año 1804 y 91 a 1807.

\section{TOMO 97}

Seguimos con las cartas de los reyes dirigidas a Manuel Godoy; 109 corresponden al año 1806 y 85 a 1807.

\section{TOMO 98}

Este tomo contiene otra colección de cartas dirigidas a Manuel Godoy, principalmente escritas por la reina María Luisa, aunque también hay algunas de su hijo, el infante Carlos Luis. Su número es muy inferior a las de los tomos 
anteriores y no sigue la cronología marcado por ellos. Contiene correspondencia de los años 1801 (8 cartas); 1802 (12 cartas); 1803 (15 cartas); 1804 (24 cartas); 1805 (21 cartas); 1806 (22 cartas); y 1807 (10 cartas).

\section{TOMO 99}

Contiene las cartas dirigidas a Manuel Godoy por parte del Duque de Parma en los años 1791 (1 carta); 1793 (13 cartas); 1794 (36 cartas); 1795 (34 cartas); 1796 (41 cartas); 1797 (26 cartas); 1798 ( 5 cartas); 1801 (3 cartas).

\section{TOMO 100 (314 folios)}

Correspondencia de Godoy con varios personajes políticos referida a asuntos de gobierno, entre los años 1796 y 1805. Algunas de las personas a las que escribió Manuel Godoy fueron: José Nicolás de Azara, diplomático destinado en Roma y luego en París; Juan Miguel de Igea; José Martínez de Hervás, marqués de Almenara; Federico Gravina, embajador de España en París. En total son 148 cartas.

TOMO 101 (264 folios)

Documentación variada (correspondencia, reales órdenes, etc.) de o para Godoy sobre diferentes asuntos de gobierno, entre los años 1801 y 1805. Algunos personajes que intervienen en este tomo son: Pablo Sangro de Merode, príncipe de Castelfranco; el general Tomás de Morla; Luciano Bonaparte; Juan de Braganza, duque de Lafoens; Luis Pinto de Sousa, vizconde de Balsemão; etc.

Predominan los documentos relativos a la guerra Hispano-francesa contra Portugal.

\section{TOMO 102}

Siguen los papeles relativos al príncipe de la Paz, Manuel Godoy. Este temo contiene correspondencia y documentación variada sobre distintos asuntos de interés para el gobierno, entre los años 1793 y 1808. Algunos de los personajes que se mencionan en este tomo son: Victor Amadeo III, rey de Cerdeña; el Conde de la Cañada; Miguel de Lardizabal, oficial mayor de la Secretaría de Estado; Antonio de los Heros, conde de Montarco y miembro del Consejo de Estado; José Caballero, ministro de Guerra; Luis de Viguri, intendente de La Habana.

TOMO 103

Este tomo contiene un poco más de 30 documentos relativos al casamiento de Manuel Godoy con María Teresa de Borbón y Villabriga. Hay algunas reales órdenes y certificaciones, pero lo que priman son las cartas de las personas involucradas, la madre de la novia, María Teresa Villabriga, la reina María Luisa y el propio Godoy.

TOMO 104

Contiene documentación personal de Manuel Godoy, desde su bautismo del 14 
de noviembre de 1731 hasta una real orden de 26 de junio de 1807 por la que se le confiere el mando de la Guardia Real. Son unos 126 documentos que abarcan una gran parte de la vida de Godoy, nombramientos, peticiones y exposiciones a los reyes, y correspondencia con los mismos.

TOMO 105

Contiene correspondencia de Manuel Godoy con distintos personajes políticos de la época, 1793-1802, relativa a las relaciones entre España y Francia. Son 50 documentos en total.

TOMO 106

Documentación que hace referencia a la relación de Fernando VII y sus padres en Roma, con todos los intermediarios que participaban es ello, principalmente Pedro Ceballos y el Duque de San Carlos. Cronológicamente van desde 1814 hasta 1817.

\section{TOMO 107}

Contiene, entre otra, la siguiente documentación: correspondencia entre Azara y Ceballos, en 1808, sobre la situación social con respecto a los franceses; informes y comunicados de la Junta de Gobierno dirigidos a Fernando VII sobre los movimientos de los franceses en la península; solicitud de instrucciones a seguir ante diferentes actos de Murat, duque de Berg; y cartas de éste dirigidas a la Junta de Gobierno.

\section{TOMO 108}

Contiene cinco cartas escritas por el Conde de Aranda entre 1777 y 1781. Van dirigidas a Bernardo del Campo, diplomático español y miembro de la Secretaría de Estado; Fernando VII, cuando aún era príncipe de Asturias; a Floridablanca, con quién mantuvo una agria enemistad política; y otras dos cartas destinadas a Fernando.

Valoración, selección y eliminación: Conservación permanente.

Nuevos ingresos: Es una serie cerrada.

Sistema de organización: cuadro de clasificación esquemático

\section{D - CONDICIONES DE ACCESO Y UTILIZACIÓN}

Condiciones de acceso: Libre consulta, por su carácter histórico, de acuerdo con el artículo 57 de la Ley 16/1985, de 25 de junio, de Patrimonio Histórico Español. Sin embargo, para su preservación, la documentación se ha microfilmado y digitalizado, y el acceso a los originales es restringido.

Condiciones de reproducción: La reproducción y el tipo está sujeta al tamaño y 
al estado de conservación de los documentos.

Lengua(s)/escritura(s): Castellano.

Características físicas y requisitos técnicos:

Instrumentos de descripción: Existen dos tomos índices, posteriores a la formación de esta serie facticia.

MORTERERO SIMÓN, Conrado. Archivo General del Palacio Real de Madrid. Inventario-Guía del fondo documental. Madrid: Patrimonio Nacional, 1977.

\section{E - DOCUMENTACIÓN ASOCIADA}

Existencia y localización de originales: De los 108 volúmenes que componen la serie, 64 se encuentran en el Archivo General de Palacio y 44 en el Archivo del Congreso de los Diputados.

Existencia y localización de copias:

Unidades de descripción relacionadas:

Nota de publicaciones:

FERNÁNDEZ MARTÍN, Manuel. Derecho parlamentario español. Tomo 3, 1814 - 1820. Segunda época. Madrid: establecimiento tipográfico hijos de J. A. García, 1900. p. 226-258.

\section{F - NOTAS \\ Nota}

\section{G - CONTROL DE LA DESCRIPCIÓN}

Nota del Archivero:

Reglas o normas: Norma ISAD (G).

Fecha de la descripción:

\section{CONCLUSIONES}

Esta serie facticia constituye una fuente fundamental para el estudio de la España contemporánea, no sólo para reconstruir la figura de Fernando VII, sino también para profundizar en aspectos políticos y sociales de su reinado, así como por los datos que proporciona de muchos otros personajes destacados en la época y de los que hay constantes referencias en la serie.

Los distintos enfrentamientos políticos que tuvo el monarca a lo largo de su reinado se ven reflejados, en mayor o menor medida, en el contenido de los Papeles Reservados: Godoy, las Cortes de Cádiz, liberales y masones, etc.

Se ha logrado establecer con seguridad la custodia o historia archivística de la serie a través de los libros de registro y elementos de descripción de los archivos consultados.

Se ofrece un análisis temático del contenido de los tomos encuadernados que 
pretende servir para hacer más fácil el uso de la serie.

Además se proporcionan una descripción archivística del fondo siguiendo la Norma Internacional de Descripción Archivística, ISAD (G)

Por último, este trabajo pretende aportar su pequeño grano de arena para dar a conocer este rico material, intentando paliar la escasa bibliografía existente sobre este tema.

\section{BIBLIOGRAFÍA CITADA Y CONSULTADA}

AENOR. Referencias bibliográficas. UNE 50-104-94. Madrid: AENOR, 1994.

BAYO, Estanislao de Kostka. Historia de la vida y reinado de Fernando VII de España: con documentos justificativos, órdenes reservadas y numerosas cartas del mismo monarca, Pio VII,... Madrid: Imprenta de Repullés, 1842.

Diccionario de Historia de España. Dirigido por Germán Bleigberg. Madrid: Alianza Editorial, 1986.

Diccionario biográfico del Trienio Liberal. Dirigido y redactado por Alberto Gil Novales. Madrid: Ediciones El Museo Universal, 1991.

Enciclopedia de Historia de España. Dirgida por Miguel Artola. T. IV. Diccionario biográfico. Madrid: Alianza Editorial, 1991.

FERNÁNDEZ MARTÍN, Manuel. Derecho parlamentario español. Tomo 3, 1814 - 1820. Segunda época. Madrid: establecimiento tipográfico hijos de J. A. García, 1900. pp. 226-258.

FERNÁNDEZ SARASOLA, Ignacio. "La primera Constitución Española: el Estatuto de Bayona". Revista de Derecho. 2006, núm. 26, p. 89

HEREDIA HERRERA, A. Archivística General Teoría y Práctica. Sevilla: Servicio de Publicaciones de la Diputación de Sevilla, 1987.

ISO. Organización Internacional de Normalización. ISO 690-1987. 1987.

MENDO CARMONA, Concepción. "Consideraciones sobre el método en archivística". Documenta \& Instrumenta 1 (2004) pp. 36-46.

MORALES RUIZ, Juan José. "Fernando VII y la Masonería española". Hispania Nova. Revista de Historia Contemporánea. 2003, núm. 3. Disponible en: http://hispanianova.rediris.es/articulos/03_002.htm >

MORTERERO SIMÓN, Conrado. Archivo General del Palacio Real de Madrid. Inventario-Guía del fondo documental. Madrid: Patrimonio Nacional, 1977.

SÁNCHEZ ALMEIDA, Angélica. Fernado VII. El Deseado. Madrid: Aldebarán, 1999.

SÁNCHEZ MANTERO, Rafael. Fernando VII. Madrid: Arlanza, 2001.

VILLAREJO SÁNCHEZ, Nadia. "Proyectos de digitalización y nuevas perspectivas tecnológicas en el Archivo histórico del Congreso de los Diputados de España: conservación de la historia del Parlamentarismo y derecho constitucional español en soporte digital". Revista Española de Documentación Científica. 2006, vol 29, núm. 4, pp. 589-602. 